International Journal of Biological Research, $2(2)(2014) 116-120$
International Journal of Biological Research
JPC \begin{tabular}{c} 
Journal home page: $\begin{array}{c}\text { www.sciencepubco.com/index.php/IJBR } \\
\text { do.14419/ijbr.v2i2.2364 } \\
\text { Research Paper }\end{array}$ \\
\hline
\end{tabular}

\title{
Brief information related to potential therapeutic tendencies of citrus plants
}

\author{
Mohammad Asif \\ Department of Pharmaceutical Chemistry, GRD (PG) Institute of Management and Technology, \\ Rajpur, Dehradun, 248009 Uttarakhand, India \\ E-mail: aasif321@gmail.com
}

\begin{abstract}
Citrus plants play an important role as a health-protector. They are containing various phytochemical that reduce or prevent risk for various diseases such as cancer, heart disease and aging effects. Citrus are good sources of naturally occurring antioxidants like vitamin $\mathrm{C}$, vitamin E, carotenes, phenolic acids, phytate and phytoestrogens that have been recognized potentially to reduce various disease risks. Some compounds, have strong antioxidant activity, while others, such as the mono-phenols are weak antioxidants. Antioxidant compounds scavenge free radicals and thus inhibit the oxidative mechanisms that lead to degenerative diseases. The free radicals may oxidize nucleic acids, proteins, lipids or DNA and can initiate degenerative disease. There are a number of studies suggesting that the antioxidants are the main factors for reducing the incidence of chronic diseases including heart disease and some cancers.
\end{abstract}

Keywords: Citrus, Antioxidants, Vitamins, Degenerative Diseases.

\section{Introduction}

The medicinal value of plants appears in all early records of human activity. The modern uses of medicinal plants or herbs, their extracts, and their semi synthetic products to treat various minor or major ailments today. It is not surprising that the taxonomic family to which citrus belongs, the Rutaceae, which includes approximately 160 genera and 1,700 species, has been used in herbal medicine. Herbs are usually defined as garden plants used secondarily in cooking for flavoring, seasoning, and garnishes for food. Herbs and herbal products have also been used medicinally for curative, preventive, remedial, and therapeutic purposes, as foods and as dietary supplements. The distinctions between herbal use and medicinal use overlap and have become blurred and therefore have to be interpreted within context (Clarke and Thaman. 1993; Kala. 2005; Continuing Survey of Food Intakes by Individuals (CSFII), 1989-1991; Ferguson. 2002).

Citrus species are small to medium-size shrubs or trees that are cultivated throughout the tropics and subtropics regions of India and southern China to northern Australia and New Caledonia. The cultivation of oranges and pummelo dates back to $2400 \mathrm{BC}$ in China. Some species can still be found in a wild state, but most species are today known only in cultivation. Citrus has been distributed widely and cultivated worldwide for fruit and juice. All species are aboriginal, early European, or modern introductions throughout Oceania. Most species have been given names in many native languages of the Pacific, attesting to how citrus has been embraced by native cultures. Citrus is adaptable to many subtropical and tropical environments and soils and has traditionally been cultivated in home gardens together with other important species such as coconut, breadfruit, papaya, and numerous others. Citrus is primarily valued for the fruit, which is either eaten alone (sweet orange, tangerine, grapefruit, etc.) as fresh fruit, processed into juice, or added to dishes and beverages (lemon, lime, etc.). All species have traditional medicinal value (Hume. 1938; Jackson and Davies. 1999; Tucker et al., 1994). Citrus has many other uses including animal fodder and craft and fuel woods (Manner et al., 2006). Size varies with species and variety. Generally, annual pruning is used to maintain tree size and shape, while stimulating fruit production. Another method of maintaining a small size is to plant varieties that are grafted to dwarfing rootstocks, or, if space is very limited, by growing the trees in large containers (Wheaton et al., 1999).

\section{Botanical description}

Genus Citrus L. Family Rutaceae (rue family) Subfamily Aurantoideae

\subsection{Subgenera: the genus citrus is further subdivided into subgenera:}

Citrus and Papeda, with the difference being the presence of acrid oil droplets in the pulp vesicles of Papeda. Most species belong to the subgenus Citrus, with C. hystrix and C. macroptera belonging to Papeda (Stone 1985). Citrus are shrubs to medium-size trees up to about $6 \mathrm{~m}(20 \mathrm{ft})$ in height, although some species can reach 15 $\mathrm{m}(50 \mathrm{ft})$. Rootstocks can greatly affect the height of grafted trees. Trees have thin, smooth, and gray-brown to greenish bark. Most species are single-trunked with very hard wood. The fruit is a hesperidium, a fleshy, indehiscent berry that ranges widely in size, color, shape, and juice quality. Citrus fruit range in size from $4 \mathrm{~cm}$ (1.6 in) for lime to over $25 \mathrm{~cm}$ (10 in) in diameter for pummelo. Fruits are globose to ovoid in shape (Thaman and Whistler. 1996; Thaman et al., 2000; Tucker et al., 1994; Tucker et al., 1994; U.S. Department of Agriculture, Agricultural Research Service. 1993). 


\subsection{Some common species, native origin, and uses in ancient time and rural areas}

Citrus aurantifolia (lime), C.aurantium(sour orange), C. grandis (pummelo), C. hystrix (Kaffir lime), C. limon (lemon), C. macroptera (wild orange), C. medica (citron), C. mitis (calamondin), C. sinensis (sweet orange), C. paradisi (grapefruit), C. reticulata (mandarin).

Lime Root, bark, stem- twigs, leaves, fruit, used in diarrhea, dysentery, colds, stomach ache, insomnia, ringworm, ulcer, fever, sore throat, wounds, eye disease, bitter tonic, sore throat, rheumatism. South China, Indochina early European introduction to $\mathrm{Pa}$ cific islands, Malaysia, Europe, Pacific islands, Malesia aboriginal introduction to Fiji, western Polynesia, and Tonga; early European introduction to other Pacific islands, SE Asia early European introduction to Pacific islands, Melanesia Polynesian introduction Vanuatu, New Caledonia, and Polynesia, India early European introduction to Pacific islands, China to many Pacific islands, West Indies recent introduction to many Pacific islands (Thaman and Whistler. 1996; Thaman et al., 2000; USDA Agricultural Research Service. 2004; Walter and Sam. 2002; Waterman and Grundon. 1983).

\subsection{Associated plant species}

In general, the flora of the native habitats of citrus consists of tropical to subtropical species in humid to subhumid environments. Most citrus species are associated with the Indomalayan flora. One exception is wild orange, which is also native to Melanesia and is therefore associated with the Melanesian floristic region. The fruit is said to achieve its highest flesh quality in subtropical humid climates or the drier regions (Mediterranean climates) with irrigation. Limes seem to be the citrus best adapted to atoll environments (Walheim. 1996; Cull and Pax. 1995). Kaffir lime is also well suited to atolls and is one of the most important sources for disease-free rootstocks for atolls.

\subsection{Look-a-like species}

All citrus species have dark green, waxy leaves with a characteristic citrus odor, and sweet-smelling flowers. Most species are easy to differentiate by their fruit. Kaffir lime and wild orange are often mistaken for each other. According to Walter and Sam (Walter and Sam. 2002), Stone (Stone. 1985) distinguished the two from each other on the basis of the fruit and thepetiole shape. Wild orange fruit has a smooth skin, and the petiole wings are entire. Kaffir lime fruit has bumpy skin, and the petiole wings are crenulate (toothed). The leaves of sour orange have a petiole that is much larger than that of sweet orange.

\subsection{Ethno botany research}

The interest in herbal use of plants, the new discipline of ethnobotany has emerged. Ethnobotany can be generally defined as the study of how people of a particular culture and region make use of indigenous or native plants. The theory was that citrus and related plants that appeared in many cultural groups were more likely to have biological activity and related uses than plants. In other words demonstrate that a number of citrus species were used for similar purposes in different locations and by different cultural groups. The observational reports as well as published biochemical, medical, and pharmacological research to establish and suggest that specific citrus species do, in fact, have specific medicinal uses (Paul and Cox. 1995). The seven following disease categories had a statistically significant number of areas for reported uses: diseases of the blood and blood-forming organs; diseases of the musculoskeletal system and connective tissue; diseases of the respiratory system; diseases of the endocrine systems; nutritional metabolic diseases and immunity disorders; infectious and parasitic diseases; injury and poisoning; symptoms, signs, and ill-defined conditions. In Samoa, a leaf infusion made from sweet orange is used against mouth sores in infants (Reuther et al., 1967; Reuther et al., 1968; Reuther et al., 1973). Citron leaves are used together with other plant parts infusions for treating stomach and skin ailments. Sweet orange bark infusion is used to treat postpartum sickness, serious flu, and internal injuries. In Tonga, an infusion of sweet orange leaves, usually together with leaves of other plants (Glochidion ramiflorum, Diospyros major), is used as to treat "relapse sickness," mostly affecting postpartum women. In Tahiti, citrus leaves are used for internal ailments and fractures. In Fiji, the scraped root of pummelo is used to treat hemorrhoids (Whistler. 1996).

\section{Medicinal uses of citrus plants and uses of their products}

All species are extremely important for their fruit in numerous ways. An extract of grapefruit seeds and pulp is used as potent topical antibacterial and fungicidal agent. Fruit juices of all species can be used in beverages. Lemon and sweet orange leaves are boiled to make tea and sour orange juice has been fermented to make wine.The herbal and medicinal value of plants appears in all early records of human activity, from the herbalists to, pharmacists, researchers and physicians of all succeeding generation, to modern use of herbs, their extracts, and synthetic products to treat minor ailments and diseases today. It is not surprising that the taxonomic family to which citrus belongs, the Rutaceae, which includes approximately 160 genera and 1,700 species, has been used in herbal medicine. Herbs are usually defined as garden plants used secondarily in cooking for flavoring, seasoning, and garnishes for food. Herbs and herbal products have also been used medicinally for curative, preventive, remedial, and therapeutic purposes, as foods and as dietary supplements. The distinctions between herbal use and medicinal use overlap and have become blurred and therefore have to be interpreted within context (Odugbemi et al., 2007; Verheij and Stone. 1991; Kamble et al., 2008; Berhow et al., 2000).

Citrus species are important in traditional medicine. In the United States, citrus is suggested as part of a healthy diet because of its high vitamin $\mathrm{C}$ content and its lycopene and flavonoids, which are known to reduce prostate and breast cancer risk, reduce viral effects and inflammation, and improve capillary activity and cholesterol levels. Recent research has focused on the biological activity of compounds found in citrus species, including compounds called flavanoids, carotenoids and limonoids, especially in terms of their effects on citrus palatability and anti-cancer activity. Citrus flavonoids have potential antioxidant (prevents aging), anti-cancer, antiviral, anti-inflammatory activities, effects on capillarity, and cholesterol-lowering ability (Stone. 1985). The principal carotenoids in pink grapefruit are lycopene and beta-carotene. Lycopene-containing fruits and vegetables have been shown to contribute to a significant reduction in prostate and mammary cancer risk. Recent studies have further shown that limonoids inhibit the development of cancer in laboratory animals and in human breast cancer cells as well as reducing cholesterol. Researchers have also suggested that, if ingested, limonoids may not be absorbed in the large intestine, and therefore could be distributed throughout the body, with beneficial effects. Since some limonoid compounds, called liminoid glycosides, are stable at high temperatures, new products incorporating these compounds could include juices, cosmetics, gums, breads, and cookies. Since mixed limonoid glucosides can be isolated in large quantities from citrus molasses, seeds, and other by-products from citrus processing plants, a supply of these compounds is readily available. Of possible interest to grapefruit growers, the concentration of these compounds varies with cultivar, harvest time, and plant tissue. In citrus species, limonoids are produced in leaves and transported to fruit and seeds, with limonoid concentration highest in the earliest stages of growth of leaves and fruit and highest in seeds during fruit growth and maturation. In leaves and fruit, total limonoid content increases during growth and maturation and decreases after maturation. 
In contrast, limonoid concentration does not decrease in seeds after fruit maturity, indicating that seeds act as storage tissues for these compounds. Interestingly, grapefruit seeds have a higher limonoid concentration on a weight basis than orange and lemon seeds. Another interesting note is that concentrations of all three classes of compounds (flavonones, carotenoids, and limonoids) vary with the fruit of different grapefruit cultivar and harvest time, with pink and red cultivars generally having greater concentrations than white cultivars earlier in the season (Berhow et al., 2000, Paul. 2000). Most species have value as flavorings, like lime and lemon are commonly used to marinate raw fish and to flavor food. Whole limes are also used in pickled. Kaffir lime leaves are used as a flavoring in cooked sauces. Citrus is one of the important honey plants in many parts of the world. The pulp and other byproducts from juice production are used as cattle feed. Birds are known to feed on varieties with seedy fruit. All species have fragrant flowers, which are very pleasant in a home garden (Kiranjot et al., 2007; Kashanipour and Mcgee. 2004).

\section{Different part of citrus plants and its uses (34-38)}

\subsection{Voletile oils/lubricant}

All the citrus plants have volatile oils in their fruits and leaves the volatile oils are usually hydrocarbons (particularly limonene) together with terpenes (which vary with each plant and give each its peculiar aroma). The volatile oil in these plants makes them useful expectorants, carminatives, diaphoretics and anti-pruritics. The volatile oils also have varying degrees of anti-microbial activity. Oils in the peel, leaf, and flower are used in cosmetics and as medicinals. The flowers of sour orange yield neroli oil, which is very important in the perfume industry. Solvents extracted from citrus peels, particularly oranges, are used in general-purpose cleaners, hand cleaners, furniture polishes, soaps, and pet shampoo. Orange oil is also used for fragrance in air fresheners, candles, and aromatherapy (Andrews and Pehrsson. 1993; Carlsen et al., 2010; Bocco et al., 1998; Bonfield and Kritchevsky. 1996).

\subsection{Acids}

Citrus fruits contain various organic acids, mainly citric. Citric acid is an important inter- mediate in body metabolic cycles. It also increases urinary secretions. Like other weak acids it is astringent. Together with the volatile oils, the acids in citrus juices exert a refrigerant (cooling) effect because of the varying degrees of sweating (diaphoresis) that they induce. Ascorbic acid of vita$\min \mathrm{C}$ is another important constituent in citrus fruits. Many studies have been made on vitamin $\mathrm{C}$ as preventive for cold. Although the value of high doses of vitamin $\mathrm{C}$ remains a controversy, it is recognized that vitamin $\mathrm{C}$ has a vital role in regulating tissue respiration. A deficiency in vitamin $\mathrm{C}$ leads to scurvy, characterized by swollen and bleeding gums, loosened teeth, weakness, swollen joints, swelling of the feet and legs and gradual development of small hemorrhages around the hair and larger bruise-like hemorrhages. Bone shafts become prone - to fracture and wounds take longer to heal. During illness and other ailments involving tissue injuries, the body's reserves of vitamin $\mathrm{C}$ are used rapidly, which is why additional vitamin $\mathrm{C}$ is prescribed during this period. Some citrus fruits juice is often given in colds, partly because it is believed that the vitamin $\mathrm{C}$ content in the fruit would be of value. The citrus fruits contain significant amounts of vitamin $\mathrm{C}$ and generally contain the recommended dietary allowance of vitamin C in 1-2 pieces of fruit (Carlsen et al., 2010; Bocco et al., 1998).

\subsection{Vitamins and polyphenols}

Citrus are good sources of antioxidants like vitamin C, vitamin E, carotenes, phenolic acids, phytate and phytoestrogens that have been recognized potentially to reduce various disease risks. Most of the antioxidant compounds of citrus plants belong to various chemical classes of compounds with a wide variety of physical and chemical properties. Some compounds, have strong antioxidant activity, while others, such as the mono-phenols are weak antioxidants. Antioxidant compounds scavenge free radicals and thus inhibit the oxidative mechanisms that lead to degenerative diseases. The free radicals may oxidize nucleic acids, proteins and lipids can initiate degenerative disease (Carlsen et al., 2010; Bocco et al., 1998).

\subsection{Alkaloids}

A number of plants from this family contain powerful alkaloids. The most familiar one would probably be apdongkahoy, whose bark is used for diarrhea, stomach pains and as an antidote for snake-bite. Apdongkahoy contains a number of quinoline-based alkaloids with powerful physiological action. (One alkaloid, lunamarine, stimulated uterine contractions in experimental animals in a concentration of 1:200,000) (Lee and Prosky. 1995; Waterman and Grundon. 1983).

\subsection{Flavonoids}

Flavonoids (yellow pigments) such as rutin, quercetin, hesperidin and naringin are present in citrus fruits. The exact role of flavanoids remains a controversy but they are said to act like vitamins, having an anti-oxidant effect. It has been claimed that citrus fruits are better sources of vitamin $C$ than synthetic preparations because of the added presence of flavonoids in the fruits. The flavonoids are said to "protect" vitamin C. At one time, the flavonoids were called "vitamin P". Citrus flavonoids have been reported to have anti-inflammatory, antibacterial and antifungal activity. There has been renewed interest in flavonoids because of reported anti-viral activity. Other flavonoids are also being studied for antifertility activity (Lee and Prosky. 1995; Waterman and Grundon. 1983).

\subsection{Minerals}

The pulp of citrus fruits is fair sources of calcium and phosphorus while the rinds carry very high levels of these minerals. 'The high calcium content and acidity of the rind make it easier for pectin to form precipitates, which is important in making jellies. Potassium is another mineral found in high levels in citrus fruits. Its content is much higher in the rind than in the pulp. Potassium is an important element needed by the body but it is easily lost in diarrhea and vomiting. Because of this, it is important to add potassium to fluid preparations being used to rehydrate patients suffering from diarrhea or vomiting, the addition of a few pieces of the rind from citrus fruits in the rehydrating fluid will solve the problem of a potassium source. Potassium is also responsible for the diuretic action of citrus fruits (Lee and Prosky. 1995; Waterman and Grundon. 1983).

\subsection{Pectin}

The rinds of citrus fruits are rich in pectin. In fact, the commercial production of pectin draws largely from the discarded rinds of citrus fruit. Pectin is an effective antidiarrheal. Pectin is a polysaccharides are polymers made up of many simple carbohydrates (sugars) linked together into long, continuous molecules. Pectin is currently valued for use as a gelling and thickening agent, beverage stabilizer, and fat substitute. Most commercial pectin is obtained by extraction from citrus peels, but sugar beet pulp is also rich in pectin. Extraction of pectin from plant material now takes an hour or more using conventional heating; care must be taken not to break down its structure which provides thickening properties-by overheating. They use less energy and yield higher quality pectin than conventional heat extraction (Fishman and Chau. 2007). 


\subsection{Fruit juice}

Citrus fruit juices can be given in colds and fever as a refrigerant and as a source of vitamin $\mathrm{C}$. The fruit juices are also helpful as an astringent for sore throats. Externally, the same astringent action is sometimes helpful for skin disorders. The application of the undiluted juice for pimples is based on the astringent effect. Fruit juice can also be used to flavor other drug preparations.

\subsection{Rind}

The rinds of ripe citrus fruits can be used in decoction for coughs, colds, indigestion and diarrhea. Gather the rinds and sundry. Store in whole pieces or cut into thin slices. The decoction can also be prepared using the rind with ginger - this is particularly helpful for nausea and vomiting. A few rinds added to rehydration preparations will provide potassium for diarrhea patients.

\subsection{Leaves}

A decoction of the leaves is used as a bath to induce sweating in patients with fever. Leaves of citrus plants are often mixed with other leaves containing volatile oils (e.g. mangga, sambong). The decoction is also of some value as a wash for skin sores and itchy conditions.

\subsection{Fiber}

The thread-like portion between the pulp and the rind can also be collected, dried and used in decoction for coughing and for general pains. About 3-5 gm of the fiber is used at a time. The dietary fibers are the remnants of plant residues (polysaccharides and lignin) which are resistant to hydrolysis by human digestive enzymes (Marlett and Vollendorf. 1994; Mongeau and Brassard. 1994).

\subsection{Seeds}

The seeds are also said to have pain-relieving effects. Place the seeds in container and add water (small amount). It store overnight then heat over a weak fire until the materials turn light yellow and dry in sun light the material and crush before using.

\subsection{Wood}

Pummelo and sweet orange wood is used in light construction. Sour orange wood is hard, fine grained, and valued for cabinetry and turnery (bowls, etc.). In Cuba, sour orange is made into baseball bats. Citrus as fuel wood is generally of minor importance. Pummelo wood is considered as good firewood. Wood of wild orange was used for axe handles and canes. Lemon wood is used for tool handles. Wild orange wood is used as the anvil in Samoa. Wood of Kaffir lime and pummelo has been noted as having importance for craft wood (Carlsen et al., 2010; Bocco et al., 1998; Bonfield and Kritchevsky. 1996).

\section{Other uses}

The macerated pulp and leaves of wild orange were used as a shampoo in Guam, Samoa, and Fiji (Walter and Sam. 2002). In Guam, Stone (Stone. 1985) noted that the pulp was used for washing clothes and hair. Stone also wrote that Kaffir lime has the same uses as wild orange and sour orange. In Chuuk, the pounded roots of a citrus species are mixed with leaves, bark, and fruit of other plants to make a perfumed precipitate for scenting necklaces, headbands, hair, and body. Sweet orange and Kaffir lime flowers are sometimes used in garlands in the Pacific islands. Kaffir lime has been noted as having potential in toxins/insecticides/fish poisons (Thaman et al., 2000.Tucker et al., 1994). Citrus can be used as a barrier hedge when trees are planted close together. Many varieties are spiny, which can enhance the effect of a hedge as a barrier. However, when hedged it takes time for trees to regrow full foliage, and if the trees do not receive ample sunlight, the regrowth occurs primarily in the tops, leaving the trunks exposed. Citrus supports bees, which produce honey. Birds often build nests within the canopy, and some will feed on the seeds, fruit, or the insects that feed on tree foliage. Snakes where present, are commonly found within the canopies. Fruit for eating or juicing is the main product from citrus grown in a landscape. Other products include leaves for cooking (e.g., Kaffir lime leaves in Thai food) and cut flowers for fragrant flower arrangements (Kamal and Mohan. 2010; Macmillan. 1991).

\section{Discussion}

In recent times, there is a growing interest in nutrition and preventive health care in the development and evaluation of natural bioactive and antioxidant active products from plant materials. It is well known that polyphenol compounds are responsible for the potential antioxidant activity and radical scavenging capacity of plant food. Consumption of a diet rich in polyphenol substances has been linked with a reduced risk for cardiovascular diseases and certain types of cancer. Dietary natural antioxidants strengthen the endogenous antioxidant system by reducing oxidative stress and the risk of toxic diseases. Radical scavenging antioxidants are particularly important in antioxidant defense to protect cells from the injurious effects of free radicals. Free radicals are very reactive chemical species, eventually evoking uncontrolled reactions, resulting in oxidative damage of important biological macromolecules. Polyunsaturated fatty acids which are major constituents of cell membranes are particularly susceptible to free-radicalmediated oxidation because of their conjugated bond structure. Consequently, the process of lipid peroxidation can lead to disturbances in membrane structure and function. Furthermore, and viewed in a global sense, polyphenol compounds as free radical scavengers can act as anti-inflammatory, antibacterial, anticarcinogenic, anti-allergic and immune-stimulating agents. Plants provide human kind with our most basic resources-food, medicine, fiber, and many other useful products. For most of human history, plants and a few fungi were the only medicines. Medicinal plants are especially likely to contain useful molecules. Some useful botanical medicines cannot readily be made into drugs. The fruit is used to treat diabetes, dysentery, cold etc. Lemon essential oil', medicated oil, is used to cleanse, refresh, cool and stimulate the skin. 'Antidandruff shampoo' is a multi-herb formulation that controls dandruff, nourishes and strengthens hair roots and ensures a healthy scalp and its medicinal applications such as for antifungal activity and weight loss.

\section{Conclusion}

Common traditionally consumed citrus plants of different origins were investigated for their content of total polyphenols and evaluated for their potential bio-active antioxidant properties, especially in reference to their comprehensive nutritional-physiological and health promoting effects: All the citrus plants showed considerable amounts of polyphenol substances. Consumption of citrus plants is helpful in maintaining and promoting health, particularly in consideration of their beneficial impact to public health, and especially in respect of cardiovascular disease prevention. Furthermore, herbal tea extracts could be regarded as effective natural antioxidant additives for food products and as functional dietary food supplements due to their significant content of total polyphenols. These are bioactive substances and have significant radical scavenging capacity. This family includes the many citrus fruits whose uses are quite similar. Since their chemical constituents and pharmacology are quite similar, they will be discussed together, according to constituents. 


\section{References}

[1] Clarke WC, Thaman RR, (Eds.). Agroforestry in the Pacific Islands Systems for Sustainability. The United Nations University, Tokyo, 1993, Japan.

[2] Kala CP. Current Status of Medicinal Plants used by Traditiona Vaidyas in Uttaranchal State of India. Ethnobotany Res. Appl., 2005 3:267-278.

[3] Continuing Survey of Food Intakes by Individuals (CSFII), 1989 1991. U.S. Department of Agriculture, Agricultural Research Service, Beltsville Human Nutrition Research Center, Food Surveys Research Group, Riverdale, MD.

[4] Ferguson JJ. Medicinal Use of Citrus. This document is HS892, one of a series of the Horticultural Sciences Department, Florida Cooperative Extension Service, Institute of Food and Agricultural Sciences, University of Florida. Publication date: October, 2002.

[5] Hume H. The Cultivation of Citrus Fruits. The Macmillan Company, 1938, New York.

[6] Jackson LK, Davies FS. Growing Citrus in Florida, 4th ed. University of Florida Presses, Gainesville, 1999, Florida.

[7] Tucker DPH, Wheaton TA, Muraro RP. Citrus Tree Pruning Principles and Practices. Fact Sheet HS-144. Institute of Food and Agricultural Sciences, University of Florida, 1994, Gainesville. http://edis.ifas.ufl.edu/CH026.

[8] Manner HI, Buker RS, SmithVE, Ward D, Elevitch CR. Species Profiles for Pacific Island Agroforestry. www.traditionaltree.org April 2006, ver. 2.1.

[9] Wheaton TA, Castle WS, Whitney JD, Tucker, DPH. Horticultural practices for citrus health. In: Timmer LW, Duncan LW, (Eds.). Citrus Health Management. APS Press, St. Paul, 1999, Minnesota.

[10]Thaman RR, Whistler WA. A Review of Uses and Status of Trees and Forests in Land-Use Systems in Samoa, Tonga, Kiribati and Tuvalu with Recommendations for Future Action. South Pacific Forestry Development Programme, Suva, 1996, Fiji.

[11]Thaman RR, Elevitch CR, Wilkinson KM. Multipurpose trees for agroforestry in the Pacific Islands. In: C.R, 2000.

[12]Tucker DPH, Albrigo LG, Wheaton TA, Parsons LR. Tree and Fruit Disorders. Fact Sheet HS-140. Institute of Food and Agricultural Sciences, University of Florida, Gainesville. http://edis.ifas.ufl.edu/CH028, 1994.

[13] Tucker DPH, Wheaton TA, Muraro RP. Citrus Tree Spacing. Fact Sheet HS-143. Institute of Food and Agricultural Sciences, University of Florida, 1994, Gainesville. http://edis. ifas.ufl.edu/CH026.

[14]U.S. Department of Agriculture, Agricultural Research Service. USDA Nutrient Data Base for Standard Reference, Rel.\#10. Springfield, VA; National Technical Information Service. 1993, Accession No. PB93-502771. Computer Diskette.

[15]USDA Agricultural Research Service. The Commercial Storage of Fruits, Vegetables, and Florist and Nursery Stocks. Agriculture Handbook 66. USDA-ARS, Beltsville, 2004, Maryland. http://www.ba.ars.usda.gov/hb66/.

[16]Walter A, Sam C. Fruits of Oceania. trans., P. Ferrar from Fruits d'Océanie. ACIAR Monograph 85. ACIAR, Canberra, 2002, Australia.

[17]Waterman PG, Grundon MF, (Eds.). Chemistry and Chemical Taxonomy of the Rutales. Academic Press, 1983, London.

[18] Walheim L. Citrus. Ironwood Press, Tucson, 1996, Arizona.

[19]Cull B, Pax L. Fruit Growing in Warm Climates for Commercial Growers \& Home Gardeners. Reed Books, 1995, Australia.

[20]Stone BC. Rutaceae. In: Dassanyake MD, Fosberg FR. (Eds.). A Revised Handbook of the Flora of Ceylon, Vol. V. Smithsonian Institution and the National Science Foundation, 1985, Washington, DC

21]Paul A, Cox PA. An Ethnobotanical Survey of Uses for Citrus Aurantium (Rutaceae) in Haiti. Economic Botany, 1995, 49:249-256. http://dx.doi.org/10.1007/BF02862342.

[22]Reuther W, Webber HJ, Batchelor LD. The Citrus Industry Volume I. University of California, 1967.

[23] Reuther W, Webber HJ, Batchelor LD. The Citrus Industry Volume II. University of California, 1968.

[24]Reuther W, Webber HJ, Batchelor LD. The Citrus Industry Volume III. University of California, 1973.

[25] Whistler WA. Tongan Herbal Medicine. Isle Botanica. Honolulu. Whistler, W.A. 1996. Samoan Herbal Medicine. Isle Botanica. 1992 Honolulu.

[26] Odugbemi TO, Akinsulire OR, Aibinu IE, Fabeku PO. Medicinal plants useful for malaria therapy in okeigbo, ondo state, southwest $\mathrm{Ni}$ geria. Afr. J. Trad. Compl. Alter. Med., 2007, 4 (2), 191-198.

27]Verheij EWM, Stone BC. 1991. Citrus L. In: E.W.M. Verheij an R.E. Coronel (Eds.). Plant Resources of South-East Asia No. 2: Edible
Fruits and Nuts. Pudoc, Wageningen, the Netherlands. http://www.proseanet.org.

[28] Kamble SY, More TN, Patil SR, Bindurani R, bodhankar SL. Plan used by tribes of northwest Maharashtra for the treatment of gastrointestinal disorders. Indian J. Trad. Knowledge. 2008, 7(2), 321-325.

[29]Berhow MA, Hasegawa S, Manners GD. (Eds.). Citrus Limonoids: Functional Chemicals in Agriculture and Foods. American Chemical Society, 2000, Washington, D.C. http://dx.doi.org/10.1021/bk-20000758

[30]Paul A. The Medicinal Use of Citrus. M.S. Thesis. Botany Dept. Univ. Fla., 2000, Gainesville.

[31] Kiranjot S, Jasjeet K, Gurvinder K, Kunwarjeet P. Prevention and Cure of Digestive Disorders Through the Use of Medicinal Plants. $J$. Hum. Ecol., 2007, 21(2): 113-116.

[32] Kashanipour RA, Mcgee RJ. Northern Lacandon Maya Medicinal Plant Use in the Communities of Lacanja Chan Sayab and Naha', Chiapas, Mexico. Kashanipour and McGee/Lacandon Maya Medicinal Plant Use. 2004, 8, 47-66.

[33] Andrews KW, Pehrsson, PR. Carbohydrate Data- Present and Future Needs. Proceedings of the 18th National Nutrient Databank Conference. Baton Rouge, LA. 1993, 164-172.

[34]Carlsen, MH, Halvorsen, BL, Holte K, Bohn, SK, Dragland S, Sampson L, Willey C, Senoo H, Umezono Y, Sanada C, Barikmo IE Berhe N, Willett WC, Phillips KM, Jacobs Jr DR, Blomhoff R. The total antioxidant content of more than 3100 foods, beverages, spices, herbs and supplements used worldwide Nut. J., 2010, 9, 3 .

[35]Bocco A, Cuvelier ME, Richard H, Berset C. Antioxidant activity and phenolic composition of citrus peel and seed extracts. J. Agri. Food Chem., 1998, 46, 2123-2129. http://dx.doi.org/10.1021/jf9709562.

[36]Bonfield C, Kritchevsky D, eds. Dietary Fiber in Health and Disease. Plenum Press, Inc. NY. Proceedings of the Fifth Vahouny Symposium, Washington, D.C., March 26-29, 1996.

[37]Lee SC, Prosky L. International Survey on Dietary Fiber: Definition, Analysis, and Reference Materials. J. AOAC Intl. 1995, 70, 22-36.

[38] Waterman PG, Grundon MF, (Eds.). Chemistry and Chemical Taxonomy of the Rutales. Academic Press, 1983, London.

[39]Fishman ML, Chau HK. Prepare orange peels for flash extraction of pectin using microwave heating under pressure. PEGGY GREB (D702-1) 16 Agricultural Res., 2007.

[40]Marlett JA, Vollendorf NW. Dietary fiber and composition of different forms of fruits. Food Chem., 1994, 51, 39-44. http://dx.doi.org/10.1016/0308-8146 (94)90045-0.

[41] Mongeau R, Brassard R. Comparison and Assessment of the Difference in Total Dietary Fiber in Cooked Dried Legumes as Determined by Five Methods. J. AOAC Intl., 1994, 77(5), 1197-1201.

[42]Kamal PA, Mohan A. Traditional knowledge on medicinal plants used for the treatment of livestock diseases in Sardikhola VDC, Kaski, Nepal. J. Med. Plants Res., 2010, 4(2), 235-239.

[43] Macmillan HF. Tropical Planting and Gardening, 6th ed., revised by H.S. Barlow, I. Enoch, and R.A. Russell. Malayan Nature Society, Kuala Lumpur, 1991, Malaysia. 